\title{
Prevalence of multiple sclerosis in the region of Osona, Catalonia, northern Spain
}

\author{
E Bufill, R Blesa, I Galan, G Dean
}

\begin{abstract}
To ascertain the prevalence of multiple sclerosis in the region of Osona in Catalonia, northern Spain, an intensive study was undertaken in a small population of 72000 people over a period of five years, using many sources of information. Patients were classified according to the Poser criteria. Most of the patients presented with mild symptoms only and many had not seen a neurologist or attended a large hospital. The prevalence of definite and probable multiple sclerosis was 58 per 100000 . This is nine to 10 times higher than had been found previously in Catalonia and is a similar prevalence to that found in southern Spain, in Sicily, and in Greek speaking Cyprus.
\end{abstract}

(F Neurol Neurosurg Psychiatry 1995;58:577-581)

Keywords: multiple sclerosis; prevalence; Catalonia; Alghero

The prevalence of multiple sclerosis - with the exception of epilepsy, the most frequent neurological disease to affect young adults in Europe and North America-was considered in the past to be uncommon in Spain, with a prevalence ranging between 5 and 23 per $100000 . .^{1-12}$ A previous study on the prevalence of multiple sclerosis in Catalonia, based on hospital records and undertaken in a large population, reported a prevalence of 6 per $100000 .{ }^{13}$ Dean and others have shown in Italy and Cyprus that when studies on multiple sclerosis are undertaken in small populations of between 30000 and 70000 people over three to five years and by using every reasonable information source, most of the patients with multiple sclerosis can be found. ${ }^{14-19}$

Most of the inhabitants of Catalonia are descended from Near East people who entered Spain during the neolithic period. Catalonia was later invaded by Phoenicians, Greeks, Romans, central and northern Europeans, and Arabs. ${ }^{20}$

Sicily had a somewhat similar genetic mix and in Sicily the prevalence of multiple sclerosis is between 50 and 60 per $100000 .{ }^{14-18}$ Alghero in Sardinia became part of the Kingdom of Aragon in 1353 and remained under Catalan domination for four centuries. Catalan is still spoken in Alghero and it is probable that many who live there have some Catalonian ancestry. In Alghero district, which has a population of 78000 , the prevalence of multiple sclerosis has been estimated to be at least 59 per $100000 .^{21}$

We had good reason, therefore, to think that the prevalence of multiple sclerosis in Catalonia might be much higher than was previously estimated. We therefore undertook an epidemiological study to ascertain the prevalence of multiple sclerosis in the region of Osona in northern Catalonia (fig 1).

\section{Method}

The Osona district in northern Catalonia consists of 52 municipalities. A municipality consists of a town and the adjacent countryside. The study area was composed of 12 adjacent municipalities situated in the centre of Osona district, surrounding the town of Vic (fig 2). Vic, situated in the centre of the district is the main town $\left(41^{\circ} 50^{\prime} \mathrm{N}-2^{\circ} 20^{\prime} \mathrm{E}\right)$. The region has a mild Mediterranean climate with a mean temperature of $12^{\circ} \mathrm{C}$. Farming and textiles are Osona's major industry.

The study was conducted from October 1989 to September 1994. 31 December 1991 was chosen as prevalence day because the last census took place in 1991. During this five year period, we searched for those who had multiple sclerosis and who were living in the area on prevalence day.

The combined population of the study area was 71985 (1991 census). The population in Osona is stable, having increased only slightly

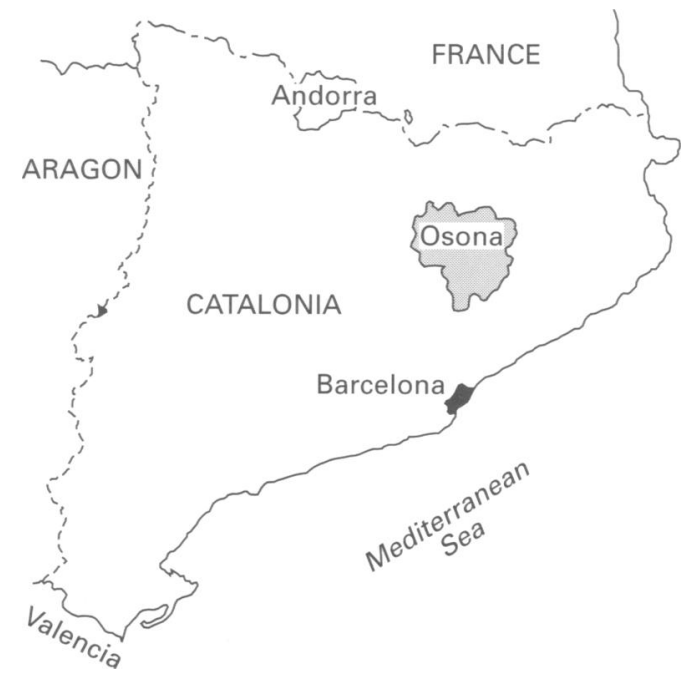

Figure 1 Map of Catalonia, showing the Region of Osona. 

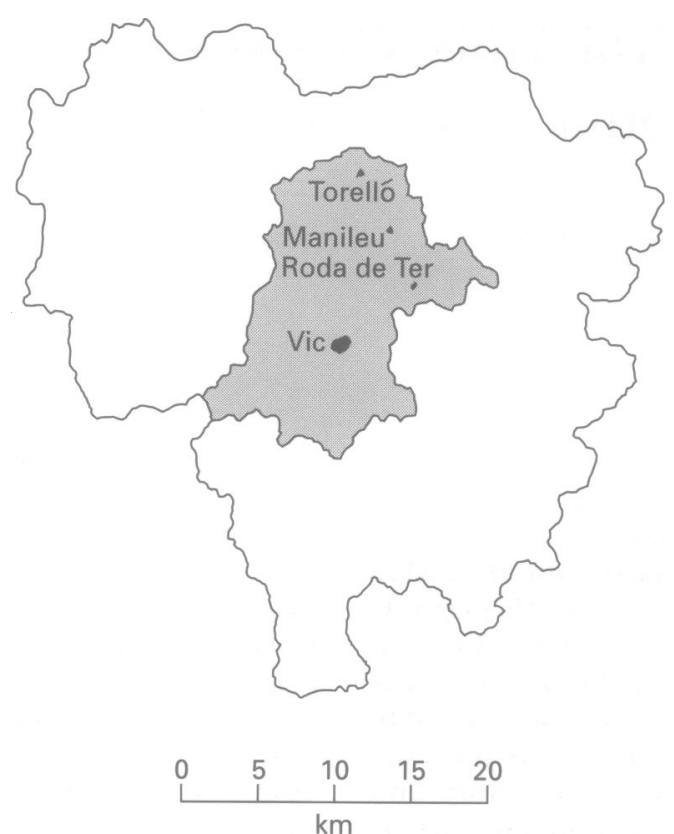

Figure 2 Map of Osona with the areas studied shown (hatched).

since 1981. The area has a well developed hospital (Hospital General de Vic), which is accredited for training postgraduate students. There are also four other hospitals in the study area and a good National Health System. During the time of the study, one of the authors (EB) was the first and only neurologist working in Osona and he examined most patients reporting with neurological problems within the region.

Barcelona, the second largest city in Spain and the principal city in Catalonia, is situated $70 \mathrm{~km}$ south of Vic. Some of the patients from the Osona district were also investigated in Barcelona at National Health System Hospitals or by private physicians. It is unusual for an Osona patient to attend at places other than in the Osona district or in Barcelona.

The Poser classification of multiple sclerosis was used ${ }^{22}$ and only those with probable or definite multiple sclerosis were included. They were all examined by two neurologists. Multiple sclerosis had to be confirmed by the second examining neurologist for the diagnosis to be accepted.

Disability was assessed with the expanded disability status scale of Kurtzke. ${ }^{23}$ A disability of 0-3 was considered mild disability, 4-6 moderate disability, and 7-9 severe disability. Patients with brucellosis, Lyme disease, syphilis, lupus, and Behçet's disease were excluded from the study. All of the patients had an MRI investigation, paid for by the Social Security Service (National Health System). An MRI was considered abnormal if there was evidence of two or more plaques in the brain or spinal cord.

Information in tracing those who might have multiple sclerosis was obtained from the local general practitioners, internists, traumatologists, surgeons, ophthalmologists, physiotherapists, social workers, and orthopaedists, and from members of the National Health
Social Security System. They included 129 general practitioners, eight internists, three ophthalmologists, five surgeons, two orthopaedic specialists, 36 social workers, and 19 physiotherapists. Initial contact with the informants was by mail (only one in four of the doctors replied), followed by a personal meeting. The personal visit with the doctors was repeated at least once a year. Some conferences describing multiple sclerosis and the purpose of the study were carried out for the non-medical personnel in the area.

Other sources of information used were the medical records of the 13 most important public and private hospitals in Barcelona that had diagnostic indices. We obtained the collaboration of the neurologists in private practice in Barcelona who might have seen patients referred by Vic doctors during the past few years (11 in total). Once a year we reviewed the records of the four MRI centres in Barcelona; 17500 records were examined. The six homes for the elderly and incapacitated in Osona were visited once a year. The disability records of the Social Security System and the records of the Spanish Multiple Sclerosis Society (AEDEM) were searched to trace patients with multiple sclerosis living in the area. The records of the Osona hospitals were also reviewed. The study was repeatedly described in the local press and on local radio and by the television stations. That the study was taking place was well known in the area. Another important source of information was the patients with multiple sclerosis, who often knew of others with similar symptoms.

The study was reviewed by the Board of AEDEM and by the Board of the Spanish Foundation for the Blind (ONCE).

\section{Results}

After an intensive search, 42 patients were found with definite or probable multiple sclerosis who were alive on prevalence day (14 men and 28 women). Thirty nine (13 men and 26 women) had clinically definite multiple sclerosis including 17 with laboratory supported clinically definite multiple sclerosis and three (one man and two women) had clinically probable multiple sclerosis. All of the patients with clinically definite multiple sclerosis had had two or more episodes of multiple sclerosis involving more than one part of the CNS and examination showed more than one lesion in the CNS.

The male:female ratio was $1: 2$. The prevalence of multiple sclerosis found in the area was 58 per 100000 (men 40 per 100000 ; women 75.5 per 100000$)$. The prevalence for clinically definite multiple sclerosis alone was 54 per 100000 (men 37 per 100000 ; women 70 per 100000$)$. The mean age at onset was 31 years (men 33, women 30) and the mean age on prevalence day was 43 years (men 46 , women 41 ). The mean period between the first symptoms and prevalence day was 12 years (13 years for men and 11 for women). Muscle weakness and disorders of sensation 
Region of Orsona: multiple sclerosis prevalence rates by age and sex

\begin{tabular}{|c|c|c|c|c|c|c|c|c|c|}
\hline \multirow[b]{2}{*}{ Age } & \multicolumn{3}{|c|}{ Population } & \multicolumn{3}{|c|}{ Patients with multiple sclerosis } & \multicolumn{3}{|c|}{ Prevalence/100 000} \\
\hline & Men & Women & Total & Men & Women & Total & Men & Women & Total \\
\hline $\begin{array}{c}\leqslant 14 \\
15-19 \\
20-24 \\
25-29 \\
30-34 \\
35-39 \\
40-44 \\
45-49 \\
50-54 \\
55-59 \\
\geqslant 60 \\
\text { Total }\end{array}$ & $\begin{array}{r}6761 \\
2877 \\
2754 \\
2910 \\
2961 \\
2640 \\
2285 \\
1899 \\
1584 \\
1957 \\
6364 \\
34992\end{array}$ & $\begin{array}{r}6285 \\
2723 \\
2638 \\
2926 \\
2922 \\
2589 \\
2319 \\
1928 \\
1769 \\
2255 \\
8639 \\
36993\end{array}$ & $\begin{array}{r}13046 \\
5600 \\
5392 \\
5836 \\
5883 \\
5229 \\
4604 \\
3827 \\
3353 \\
4212 \\
15003 \\
71985\end{array}$ & $\begin{array}{r}- \\
- \\
1 \\
1 \\
3 \\
2 \\
2 \\
1 \\
2 \\
2 \\
14\end{array}$ & $\begin{array}{r}-1 \\
2 \\
2 \\
4 \\
5 \\
4 \\
4 \\
2 \\
1 \\
3 \\
28\end{array}$ & $\begin{array}{r}- \\
1 \\
2 \\
3 \\
5 \\
8 \\
6 \\
6 \\
3 \\
3 \\
5 \\
42\end{array}$ & $\begin{array}{l}- \\
\overline{1} \\
34 \cdot 3 \\
33 \cdot 7 \\
113 \cdot 6 \\
87 \cdot 5 \\
105 \cdot 3 \\
63 \cdot 1 \\
102 \cdot 1 \\
31 \cdot 4 \\
40\end{array}$ & $\begin{array}{r}- \\
36.7 \\
75.8 \\
68.3 \\
136.8 \\
193.1 \\
172.4 \\
207.4 \\
113 \\
44.3 \\
34.7 \\
75.5\end{array}$ & $\begin{array}{r}17 \cdot 8 \\
37 \\
51 \cdot 4 \\
84 \cdot 9 \\
152 \cdot 9 \\
130 \cdot 3 \\
156 \cdot 7 \\
89 \cdot 4 \\
71 \cdot 2 \\
33 \cdot 3 \\
58\end{array}$ \\
\hline
\end{tabular}

were the most frequent initial symptoms, followed by vertigo, optic neuritis, diplopia, and cerebellar and bladder symptoms. The table shows the prevalence rate by age and sex. The mean number of years between the first symptoms and a diagnosis of multiple sclerosis was five and ranged from 0 to 46 years. No patients refused an examination or a brain MRI. Brain MRI was abnormal, with evidence of multiple plaques, in 34 patients and normal in eight patients. Spinal cord MRI was performed in 12 of the 34 patients with evidence of brain plaques and was abnormal in nine. Spinal cord MRI was also performed in three of the eight patients with normal brain MRI and was abnormal in all three, with evidence of two or more plaques. The remaining five patients with normal brain MRI refused an MRI of the cord. All of the previously undiagnosed patients with multiple sclerosis were pleased that the cause of their symptoms had been found.

The mean disability of the patients, assessed with the expanded disability status scale, was four ( 4.5 for men and 3.5 for women) and the progression index was 0.33 . Twelve patients were alive 20 years after the first symptoms; four of them had mild disability, three had moderate disability, and five had severe disability.

Thirty two of the 42 patients with multiple sclerosis $(76 \%)$ had remitting-relapsing multiple sclerosis ( 9 men and 23 women). Six $(14 \%)$ had initially remitting-relapsing multiple sclerosis, which was then followed by a progressive form of the disease (two men and four women) and four (9.5\%) had chronicprogressive multiple sclerosis (three men and one woman). The most severe disabilities were seen in the patients with chronicprogressive multiple sclerosis.

Twenty nine patients were born in the study area $(69 \%)$; five were born elsewhere in Catalonia (12\%) and eight were newcomers to Catalonia (six from southern Spain, one from central Spain, and one from Mexico). One patient had a sister, not living in the area, who also had multiple sclerosis.

Only $18(43 \%)$ of the patients had already been diagnosed as having multiple sclerosis and been seen by a neurologist. Nineteen (45\%) had had symptoms without having been diagnosed, five of them for more than 10 years, and five (12\%) had been misdiagnosed. There were also seven patients diagnosed as having possible multiple sclerosis and six who had optic neuritis only, who have not been included in the study. Five of the patients with possible multiple sclerosis had normal brain MRI and two had abnormal brain MRI but they did not fulfil sufficient criteria to be diagnosed as clinically definite or clinically probable multiple sclerosis. Four of the patients with optic neuritis only had normal brain MRI and MRI was not performed in the other two patients with a history of optic neuritis because they had had the optic neuritis more than 20 years ago and they had had no symptoms suggesting multiple sclerosis since then.

Ten of the 19 undiagnosed patients were referred by general practitioners and seven by internists, and two asked to be examined without a referral after learning of the study. Two of the five misdiagnosed patients were referred by internists with the diagnosis of hysteria, one by a general practitioner with the diagnosis of craniocerebral trauma, one by a traumatologist with the diagnosis of peripheral nerve disease, and one was found in a nursing home diagnosed as having myelopathy of unknown origin. All 18 patients diagnosed as having multiple sclerosis had been diagnosed by neurologists in Barcelona, 15 at National Health System hospitals and three by private consultation. One female patient diagnosed as having multiple sclerosis at a Barcelona hospital was not included in the study because an MRI showed that she had Arnold-Chiari syndrome.

Since prevalence day two patients have moved out of the area and one has died, and four new patients were diagnosed as having multiple sclerosis; three clinically definite (two men, one woman) and one clinically probable (man).

\section{Discussion}

The estimated prevalence of multiple sclerosis in the district of Osona that we studied (58 per 1000000 ), is nine to 10 times higher than previously reported in Catalonia and is higher than has been reported elsewhere in Spain. It is similar to the prevalence found in Sicily and Cyprus and in Alghero, Sardinia. In the study undertaken in Velez-Malaga in southern Spain, with similar methods, the prevalence of multiple sclerosis was also high (53 per $100000),{ }^{24}$ not significantly different from the 
prevalence of multiple sclerosis we found in Osona.

In the studies undertaken in Asturias in northern Spain ${ }^{11}$ and in Alcoy in eastern Spain $^{7}$ in 1988 and 1989 (prevalence 23 per 100000 and 17 per 100000 respectively) the incidence for the disease was $1 \cdot 5 / 100000 /$ year and $2 \cdot 9 / 100000 /$ year. If the mean survival of the patients with multiple sclerosis from the beginning of the disease is at least 30 years, the "true" prevalence in these areas must be similar to that found in Velez-Malaga and in Osona.

It is unlikely, therefore, that the prevalence found in Osona and Velez-Malaga represents clusters for the disease and it would seem probable that the prevalence of definite and probable multiple sclerosis in Spain is at least 50 to 60 per 100000 . Nevertheless, one or two more studies about prevalence of multiple sclerosis should be done in other areas of the country to confirm this relatively high prevalence.

The high prevalence found in Osona and in Velez-Malaga, compared with previous studies in Spain, is due to the study of small populations during long periods and the use of many sources of information. Personal interviews are very important in such studies. In this study most of the letters that were sent to doctors about the survey were not answered but the doctor was always prepared to meet and discuss the study.

Most of the patients with multiple sclerosis had only mild symptoms and most had not seen a neurologist or visited a large hospital. This raises the likelihood that there are others who have had mild symptoms, such as paraesthesia, who remain undiagnosed. In view of the widespread publicity of the study in the area and the many sources of information used, there were probably only a few overlooked with diagnosable multiple sclerosis.

In many studies recent multiple sclerosis surveys have shown a much higher prevalence than earlier ones. ${ }^{14-19}$ Patients with multiple sclerosis no doubt live longer than in the past because of better treatment of the complications of the disease but this alone could not account for the very great increase in prevalence that has been reported. Repeated surveys, particularly if undertaken in an intensive way on a relatively small population, are built on the earlier surveys among a population and among doctors who have an increased awareness of the disease. In the present study only 18 out of the 42 patients with multiple sclerosis $(43 \%)$ had already been diagnosed as having the disease. In all probability if this study is repeated in a few years time a higher prevalence of multiple sclerosis will be found. Some autoimmune disorders in Europe, such as asthma, have increased in incidence. That there is little or no increase in incidence of multiple sclerosis is supported by the surveys of multiple sclerosis in Denmark, where the incidence of multiple sclerosis has, if anything, fallen, ${ }^{25}$ and by the reported mortality from multiple sclerosis in England and Wales and the Republic of Ireland, which has not increased, although there is evidence that patients with multiple sclerosis are living longer. ${ }^{26}$

The studies in Osona and Velez-Malaga show that multiple sclerosis is much more prevalent in Spain than was previously thought and afflicts at least 50 to 60 per 100000 of the population.

We thank AEDEM, in particular the Chairman at the time of the study, Mr Alberto Sainz, Madrid, and the Vice President, Ms Rosa Maria Estrany of the AEDEM Headquarters, Barcelona, who initiated and encouraged this study.

Financial support was obtained from ONCE, AEDEM, and he Consell Comarcal d'Osona.

Dr Jordi Casabona, the Government of Catalonia's epidemiologist and Dr Xavier Navarro, Neurophysiology Professor at the University of Barcelona, reviewed the protocol of the study.

We also thank the many people and institutions who made this study possible; the staff of the Hospital General de Vic and the Hospital Clinic i Provincial de Barcelona (Neurology Department), Dr Joan Brugués, Dr Francesc Graus, Dr Josep Bagunya, Dr Teresa Vilardell, Dr Teresa Gerard, Dr Maria
Angels Moleiro, Dr Josep Maria Aragonés, Dr Mercè Molist, Dr Montserrat Pujol, Dr Adria Arboix, and Ms Francesca Villodre.

This study has been awarded the prize "Primer Premi Sanitat a Osona 1993" by the Medical Association of Barcelona (Col legi de Metges de Barcelona).

1 Matthews WB, Compston A, Allen IV. McAlpine's multiple sclerosis. 2nd ed. Churchill Livingstone, 1991.

2 Miro J, Rebollo M, Combarros O, Polo JM, Lerro C, Berciano J. Esclerosis multiple en Cantabria. Estudio retrospectivo de 30 casos. Rev Clin Esp 1984;175:153-5.

3 Sosa M, Betancor P, Rosas C, Navarro MC. La esclerosis multiple en la provincia de Las Palmas. Archives de Nultiple en la provincia de Las Palogia (Madrid) 1983;46:161-6.

4 Barduzal-Angles S, Oliveros Juste A, Manubens Bertren JM, Morales Asin F. Esclerosis multiple: estudio epidemiologico retrospectivo en Aragon (1975-1985) Neurologia 1987;2:97-100

5 Fernandez $O$, Izquierdo $G$, Campos VM, Pastor $M$. Epidemiologia de la esclerosis multiple en la provincia de Malaga (Espana). Un estudio de prevalencia. Neurologia 1986;1:3-11.

6 Ruiz Esquerro JJ, Ortin Castano S, Lopez Alburquerque J, Lopez Garcia M, Cacho Gutierrez J. Epidemiologia de la esclerosis multiple (Salamanca y Zamora). Neurologia 1988;3 (suppl):35.

7 Matias Guiu J, Bolumar F, Martin R, Insa R, Casquero P, et al. Multiple sclerosis in Spain: an epidemiological study of the Alcoy health region, Valencia. Acta Neurol Scand 1990;8:479-83.

8 Anton E, Maravi Petri E, Martinez-Lage JM, Gallego J. Epidemiologia de la esclerosis multiple en Navarra. Epidemiologia de la esclerosis multiple en Navarra. Analisis retrospectivo. Neurologia 1988;3 (suppl 3):18.
Anton-Aranda E, Martinez-Lage JM, Maravi Petri E, Anton-Aranda E, Martinez-Lage JM, Maravi Petri E,
Gallego Cullere E. De Castro P, Villanueva Eusa JA. Epidemiologia y aspectos clinicos evolutivos de la esclerosis multiple en Navarra. Neurologia 1991;6:160-9.

10 Garcia JR, Rodriquez S, Sosa-henriquez M, Batista E, Corujo E, Font de Mora Turon A, et al. Prevalence of multiple sclerosis in Lanzarote (Canary Islands). Neurology 1989;39:265-7.

11 Uria DF, Virgala P, Alonso P, Crespo JR, Calatayud T, Arribas JM. Epidemiologia de la esclerosis multiple en Asturias. Neurologia 1991;6:41-5.

12 Navarro X. Geographical distribution of multiple sclerosis mortality in Spain. Acta Neurol Scand 1987;76:306-9.

13 Oliveras De Lariva C, Aragones Olle JM, Mercade Sobreques J. Estudio de la incidencia relativa y absoluta de la esclerosis multiple en nuestra region. Anales de Medicina y Cirugla (Barcelona) 1968;54:13-5.

14 Dean G, Grimaldi G, Kelly R, Karhausen L. Multiple sclerosis in southern Europe I: prevalence in Sicily in 1975. F Epidemiol Community Health 1979;33:107-10

15 Savettieri G, Daricello B, Giordano D, Karhausen L, Dean G. The prevalence of multiple sclerosis in Sicily. Monreale City. $\mathcal{F}$ Epidemiol Community Health 1981; 35:114-7.

16 Savettieri G, Elian M, Giordano D, Grimaldi G, Ventura A, Dean G. A further study on the prevalence of multiple sclerosis in Sicily: Caltanissetta City. Acta Neurol Scand 1986;73:71-5.

17 Dean G, Savetrieri G, Giordano D, Butera C, Taibi G, Morreale S, Karhausen L. The prevalence of multiple sclerosis in Sicily: Agrigento City. $f$ Epidemiol Community Health 1981;30:118-22.

18 Morganti G, Naccarato S, Elian M, Ferrari P, Kelly R, Karhausen L, Dean G. Multiple sclerosis in the Republic of San Marino. I Epidemiol Community Health 1984;38:23-8.

19 Middleton LT, Dean G. Multiple sclerosis in Cyprus. $\mathcal{f}$ Neurol Sci 1991;103:29-36. 
20 Bertranpetit J, Cavalli-Sforza LL. A genetic reconstruction of the history of the population of the Iberian Peninsula. Ann Hum Genet 1991;55:51-67.

21 Rosati G, Aiello I, Pirastru MI, Mannu L, Demontis G, Becciu $S$, et al. Sardinia-a high-risk area for Becciu S, et al. Sardinia-a high-risk area for in the district of Alghero. Ann Neurol 1987;21:190-4.

in the district of Alghero. Ann Neurol 1987;21:190-4.

Poser CM, Paty DW, Scheinberg L, McDonald WI, Davis FA, Ebers GC, et al. New diagnostic criteria for multiple sclerosis: guidelines for research protocols. Ann Neurol

1983;13:227-31.
23 Kurtzke JF. Rating neurological impairment in multiple sclerosis: an expanded disability status scale (EDSS).
Neurology 1983;33:1444-52.

24 Fernandez O, Luque G, Bravo M, San Roman C, Bravo $M$, Dean $G$. The prevalence of multiple sclerosis in the Sanitary District of Vélez-Malaga, southern Spain. Neurology 1994;44:425-9.

25 Warren S. Epidemiology of multiple sclerosis. In: Anderson DW, Schoenberg DG, eds. Neuroepidemiology: a tribute to Bruce Schoenberg Baton Rouge, FL: CRC Press Inc 1991:239-58.

26 Elian M, Dean G. The changing mortality from motor neurone disease and multiple sclerosis in motor neurone disease and multiple sclerosis in Neuroepidemiology 1992;11:236-43.

NEUROLOGY IN LITERATURE

\section{Some neurological opinions}

The borderlands of neurology and psychiatry have clearly been thoroughly trodden by some of the neurologists quoted here. Dr Spitz's satisfaction at diagnosing his patient's dizziness seems undiminished by his subsequent suicide. There are, one fears, several modern equivalents of $\mathrm{Dr}$ Greatorex, with not a few to be found in a particular thoroughfare in W1! Silas Weir-Mitchell's treatment, mentioned in Arnold Bennett's novel, is described by Gowers ${ }^{1}$ as "keeping the patient absolutely at rest in bed, and obtaining the tonic influence of exercise by daily massage and electricity - skilled rubbing and kneading the muscles, and putting them in action by faradism."

Proust seems to believe that Charcot was responsible for describing the light fixed pupil in tertiary syphilis, an attribution that no doubt would have surprised Argyll Robertson.

Wilkie Collins, 1883, Heart and science

"Doctor Benjulia is what we call a specialist," he said. "I mean that he only professes to treat certain diseases. Brains and nerves are Benjulia's diseases. Without quite discontinuing his medical practice, he limits himself to serious cases-when other doctors are puzzled, you know, and want him to help them."

Thomas Hardy, undated, The fiddler of the reels

The next evidences of his influence over her were singular enough, and it would require a neurologist to fully explain them.

Arnold Bennett, 1907, The grim smile of the five towns The doctor mentioned Greatorex of Manchester, the celebrated brain specialist. And Horace took Sidney to Manchester. They had to wait an hour and a quarter to see Greatorex, his well-known consulting-rooms in John Dalton Street being crowded with imperfect brains; but their turn came at last, and they found themselves in Greatorex's presence. Greatorex was a fat man, with the voice of a thin man, who seemed to spend the whole of his career in the care of his fingernails ..."Yes, Yes, Yes, Yes, Yes!" Greatorex would punctuate the recital, and when tired of "Yes" he would say, "Hum, Hum, Hum, Hum!" When he had said "Hum" seventy-two times he suddenly remarked that his fee was three guineas, and told Horace to strengthen Sidney all he could, not to work him too hard, and to bring him back in a year's time.

Arnold Bennett, 1918, The pretty lady

"But I was under the impression you were cured."

"Of my neurasthenia?"

"Yes"

"I believe I am. I gained thirteen pounds in the Nursing Home, and slept like a greengrocer. In fact, the Weir-Mitchell treatment, with modern improvements of course, enjoyed a marvellous triumph in my case."

Marcel Proust, 1920-2, Remembrance of things past. Volume 2: the Guermantes Way; Cities of the plain
I now gave $\mathrm{Dr} \mathrm{Du}$ Boulbon the benefit of that unlimited confidence which is inspired in us by the man who, with an eye more penetrating than other men's, perceives the truth. I knew indeed that he was more of a specialist in nervous diseases, the man to whom Charcot before his death had predicted that he would reign supreme in neurology and psychiatry.

But I am dumbfounded when I think that those words have sufficed to keep Socrates' name alive all this time. What does his philosophy amount to? Very little when all is said. When one thinks that Charcot and others have done work that is a thousand times more remarkable and is at least based on something, on the suppression of the pupillary reflex as a syndrome of general paralysis, and that they are almost forgotten.

Karel Capek, 1926, Tales from two pockets

Of course, they began to consult all sorts of doctors about it, and as generally happens in cases like that, one bone setter said that the attacks of giddiness were due to overwork, another one explained that it was a disease known as labyrinthitis, a third put it down to constipation, while a fourth expressed the view that it was caused by an insufficiency of blood in the brain;... At this juncture, a new doctor, a neurologist, began to perform miracles-Spitz his name was; this Dr Spitz based his method on the treatment of these repressions ... "Mr Gierke," said Dr Spitz to him, "I'm not going to worry you; you needn't answer me a single word. I won't ask you about anything. All I want to do is to remove the cause of your attacks of giddiness. You have thrust it down into your subconscious; but the repression is so strong that it produces serious disturbances." ... "When you first had that fit of giddiness on the campanile at Venice, try and remember what your feelings were at the time.". . "What you felt was," continued Dr Spitz, "-What you felt was a dreadful, mad craving to throw your beautiful young wife down from the belfry". . "Gierke," exclaimed Dr Spitz, "You murdered your first wife. You pushed her over the precipice; and that's why, I tell you, that's why you've got the idea that you'll have to kill the second one as well, the one you're in love with; that's why you're afraid of heights; that's why you're troubled with giddiness." ...

- Gierke commits suicide-

When Dr Spitz was told about it, he whistled to himself and made a very peculiar face. Then he took the book in which he entered the names of his patients, and opposite Gierke's name he just added the date and the one word "Suicidum."

George Orwell, 1949, Nineteen eighty-four

We shall abolish the orgasm. Our neurologists are at work upon it now. Regional Neurosciences Centre, Charing Cross Hospital, London W6 8RF, UK

1 Gowers WR. A manual of disease of the nervous system. 2nd ed. London: J and A Churchill, 1893;2:1022. 